history of TB and one was HIV positive. All patients presented with a breast lump, $58 \%$ in the upper outer quadrant. 25 patients initially presented to their general practitioner (GP), of which 24 were referred to breast clinic and 1 directly to TB clinic. Eight cases presented to hospital. In two cases there was insufficient data. The breast lump was associated with skin changes in six cases, inverted nipple in three, discharge in one, and $49 \%$ had ipsilateral axillary lymphadenopathy. Erythrocyte sedimentation rate and C-reactive protein was raised in $84 \%$ and $53 \%$ cases respectively. Thirty percent of patients had abnormal mammography, 68\% abnormal ultrasound breast findings. 25 out of 35 cases had biopsies/fine needle aspirations (FNA), all of these were sent for culture; 17 were culture positive with 3 drug resistant cases. Nine cases had necrotising granulomatous changes on histology, of which 1 was positive for Ziehl-Neelson $(\mathrm{ZN})$ stain, 9 cases had non-necrotising granulomas, of which 2 were $\mathrm{ZN}$ positive, and 7 cases had inflammatory changes only (none were $\mathrm{ZN}$ positive). All patients received at least three antituberculous drugs. Median treatment duration was six months, leading to complete resolution of breast TB.

Conclusion This case series highlights the difficultly in diagnosing breast TB. Raising awareness of the classical presentation of breast TB amongst GPs and breast services may improve diagnosis and treatment of this rare disease.

\section{P258 MULTI-DRUG RESISTANT TUBERCULOSIS MONITORING GUIDANCE: ARE WE FOLLOWING THE NATIONAL GUIDELINES?}

S Parmar, R Singal, H Khachi. Barts Health NHS Trust, London, UK

\subsection{6/thoraxjnl-2015-207770.394}

Introduction Multi-Drug Resistant Tuberculosis (MDR-TB) is a form of TB that is resistant to the two most powerful first-line anti-tuberculosis antibiotics available, rifampicin and isoniazid. Between 2004 and 2011, the proportion of cases with MDR-TB increased from $1.2 \%$ to $1.6 \%$, of which it has remained stable over the past 3 years. Due to the complexity of treatment regimens used for MDR-TB, national monitoring guidelines have been developed to aid monitoring for adverse effects during treatment. ${ }^{1}$ A previous study identified that prior to the development of these monitoring guidelines the incidence of adverse effects associated with MDR TB medicines was high. ${ }^{2}$

Objective To establish whether national guidelines for the monitoring of MDR-TB medicines at a tertiary centre are being adhered to.

Results 9 patients with MDR-TB were included in the audit. The findings (see Table 1) show that baseline monitoring was not undertaken in the majority of patients. Whilst on-going monitoring was predominantly undertaken in over $80 \%$ of occasions, the audit standard was not met.

Conclusions Despite the presence of national guidance to support the monitoring of complex regimens for MDR-TB, this audit shows that monitoring of these in a tertiary centre is below the audit standard. Whilst adherence to on-going monitoring parameters were usually undertaken in over $80 \%$ of instances, it is of particular concern that baseline monitoring was significantly below the audit standard. Pharmacists are ideally placed to support the safe and effective monitoring of these often toxic medicines. The development of a pharmacist to support the TB clinics and specifically to support the monitoring of patients with MDR-TB could significantly improve this adherence and reduce the risk of adverse effects as a result of sub-optimal monitoring.

\begin{tabular}{|c|c|c|c|c|}
\hline Drug & $\begin{array}{l}\text { Number of } \\
\text { patients taking } \\
\text { drug }[n=9]\end{array}$ & $\begin{array}{l}\text { Baseline } \\
\text { monitoring } \\
\text { carried out } \\
(\%)\end{array}$ & $\begin{array}{l}\text { On-going } \\
\text { monitoring } \\
\text { carried out } \\
(\%)\end{array}$ & $\begin{array}{l}\text { Drug specific } \\
\text { monitoring } \\
\text { carried out }(\%)\end{array}$ \\
\hline Amikacin & 6 & $58 \%$ & $85 \%$ & $91 \%$ \\
\hline Capreomycin & 1 & $81 \%$ & $85 \%$ & $100 \%$ \\
\hline Clofazamine & 3 & $71 \%$ & $90 \%$ & $55 \%$ \\
\hline Co-amoxiclav & 3 & $38 \%$ & $77 \%$ & $N / A^{*}$ \\
\hline Cycloserine & 9 & $61 \%$ & $82 \%$ & $91 \%$ \\
\hline Ethambutol & 4 & $64 \%$ & $84 \%$ & $52 \%$ \\
\hline Linezolid & 4 & $66 \%$ & $82 \%$ & $48 \%$ \\
\hline Moxifloxacin & 6 & $72 \%$ & $84 \%$ & $17 \%$ \\
\hline PAS & 4 & $53 \%$ & $82 \%$ & $94 \%$ \\
\hline Prothionamide & 8 & $60 \%$ & $83 \%$ & $53 \%$ \\
\hline Pyrazinamide & 3 & $46 \%$ & $71 \%$ & $N / A^{*}$ \\
\hline Rifampicin & 1 & $69 \%$ & $72 \%$ & $N / A^{*}$ \\
\hline
\end{tabular}

*Drugs did not require specific monitoring, according to drug monographs.

\section{REFERENCES}

1 Potter JL, Capstick T. A UK based resource to support the monitoring and safe use of anti-tuberculosis drugs and second line treatment of multi-drug resistant tuberculosis. First published May 2014, Latest update January 2015

2 Keal JL, Khachi H, Hanzaree $\mathrm{E}$, et al. Treatment of multidrug resistant tuberculosis: where are the guidelines for monitoring? Thorax 2011;66(Suppl 4):A91

\section{P259 CENTRAL NERVOUS SYSTEM TUBERCULOSIS: DIAGNOSTIC DIFFICULTIES}

L Macpherson, R Cuthbert, J Potter, V White, N Jayasera, H Kunst. St. Bartholomew's and the London NHS Trust, London, UK

\subsection{6/thoraxjnl-2015-207770.395}

Introduction Central nervous system (CNS) tuberculosis (TB) is difficult to diagnose. There is often a delay in diagnosis and a lack of robust diagnostic criteria.

Methods We conducted a retrospective study of all patients treated at our institution for CNS TB from 2009-2014 excluding those with HIV co-infection. Data including demographics, symptoms, microbiological and radiological features was recorded.

Results 55 cases of CNS TB were identified. The mean age was 36 (4 months -81 years). Most patients were from the Indian Subcontinent (70.9\%), 10.8\% were from South East Asia, 1.8\% from Africa, 10.9\% were UK born and 5.5\% were unknown. Symptoms and signs at presentation included headache (67.3\%), fever (49\%), confusion (34.5\%), focal neurological deficit (27.3\%), weight loss (27.3\%), night sweats (23.6\%), altered GCS $(23.6 \%)$ and seizures (20\%). 29\% of patients also had pulmonary TB, $11 \%$ had TB lymphadenopathy and $11 \%$ had miliary TB.

$89 \%$ of patients had a CT head, of which $42.8 \%$ were reported normal, $28.5 \%$ reported tuberculomas, $14.2 \%$ hydrocephalus and $20.4 \%$ exhibited other abnormalities. $87 \%$ had an MRI head, of which $10 \%$ were normal, $39.6 \%$ reported tuberculomas, 33\% meningeal enhancement, 6\% hydrocephalus, and $23 \%$ demonstrated other abnormalities.

Lumbar puncture (LP) was performed in $73 \%$ of cases, and CSF protein was elevated in $73 \%$ of these. The WCC was elevated in $60 \%$ with $63 \%$ having a predominant lymphocytosis. 